Artigo de Revisão

Hegemonia - Revista Eletrônica do Programa de Mestrado em Direitos Humanos, Cidadania

e Violência/Ciência Política do Centro Universitário Unieuro

ISSN: $1809-1261$

UNIEURO, Brasília, número 27 (Especial), 2019, pp. 7-42.

Recebido em: 12/9/2018

Avaliado em: 29/10/2018

Aprovado em: 21/11/2018

\title{
LÁTEX COMO BIOMATERIAL E SUAS POTENCIALIDADES NA ÁREA MÉDICA
}

\author{
Maria do Socorro de Lima Silva ${ }^{1}$, Ludmila Evangelista dos Santos², Glécia Virgolino da Silva \\ Luz ${ }^{3}$, José Carlos Tatmatsu Rocha ${ }^{4}$, e Aldene Guimarães Duarte Dantas ${ }^{5}$
}

Resumo: O látex é uma borracha natural obtida da árvore Hevea brasiliensis da região norte brasileira. Este material possui diversas aplicações na indústria, por sua propriedade viscoelástica e potencialidades de aplicação na área têxtil, automotiva, médica, entre outras. Perante tal fato, o presente artigo tem por objetivo investigar as publicações científicas realizadas, nos últimos cinco anos, sobre as potencialidades do látex como biomaterial na área médica. Os trabalhos científicos selecionados foram obtidos nas bases de dados: Elsevier (CrossRef), Medline/Pubmed (NLM), Science Citation Index Expanded (Web of Science), Scopus (Elsevier), SCIELO, LILACS, Google acadêmico,Clinicaltrials.gov, Science Direct e na plataforma Periódicos CAPES. Acessados o portal Periódicos CAPES, utilizou-se as palavraschaves "biomaterial", "biomedical engineering", "health", "medicine" e "latex", e com período de busca de 2014-2018, para artigos revisados por pares. Como resultado desta pesquisa bibliográfica, verificou-se que o látex tem sido utilizado, principalmente, em regeneração óssea com $21,52 \%$ das publicações obtidas. 14,91\% apresentaram estudos na área de estética e 14,69\% na área de oftalmológica, entre outras aplicações. Observou-se que as perspectivas futuras para o uso de látex têm crescido significativamente nos últimos cinco anos, gerando benefícios à sociedade pela sua ação terapêutica e pela geração de empregos na sua obtenção.

Palavras-Chave: biomaterial, engenharia biomédica, saúde, medicina e látex.

Abstract: Latex is a natural rubber obtained the tree Hevea brasiliensis in Brazilian north region. This material has many applications in industry, for your viscoelastic property and potential applications in the textile, automotive, medical area, among others. Faced with this fact, this article aims to investigate the scientific publications held in the past five years, about the potential of latex as biomaterial in the medical field. The scientific papers were selected with

\footnotetext{
1 Graduanda em Tecnóloga em Radiologia pela Faculdade Juscelino Kubistchek, aluna especial no Programa de Pós-Graduação em Engenharia Biomédica-PPGEB da Universidade de Brasília-UnB.

${ }^{2}$ Graduada em Engenharia de Energia e aluna especial no Programa de Pós-Graduação- PPGEB da Universidade de Brasília-UnB.

${ }^{3}$ Química, Doutora em Engenharia Mecânica e Pesquisadora Colaboradora do Programa de Pós-Graduação em Engenharia Biomédica da Universidade de Brasília, Faculdade Gama-FGA. Pesquisadora do Laboratório de Nanotecnologia - NANOTEC-FGA/UnB.

${ }^{4}$ Fisioterapeuta, Doutor em Fisioterapia, Professor adjunto da Universidade Federal do Ceará-UFC e Pesquisador Colaborador do Programa de Pós-Graduação em Engenharia Biomédica da Universidade de Brasília, Faculdade Gama-FGA.

${ }^{5}$ Graduada em Pedagogia, aluna do Programa de Pós-Graduação em Engenharia Biomédica da Universidade de Brasília-UnB.
} 
Artigo de Revisão

Hegemonia - Revista Eletrônica do Programa de Mestrado em Direitos Humanos, Cidadania

e Violência/Ciência Política do Centro Universitário Unieuro

ISSN: 1809-1261

UNIEURO, Brasília, número 27 (Especial), 2019, pp. 7-42.

Elsevier (CrossRef), Medline / Pubmed (NLM), Science Citation Index Expanded (Web of Science), Scopus (Elsevier), SCIELO, LILACS, Google academic, Clinicaltrials.gov, Science Direct and on the Periódicos CAPES platform. Accessed through the Periódicos CAPES website, the keywords "biomaterial", "biomedical engineering", "health", "medicine" and "latex" were used as keywords for the review period for 2014-2018, for peer-reviewed articles. As a result of this literature search, it was found that latex has been used mainly in bone regeneration with $21.52 \%$ of the publications obtained. $14.91 \%$ presented studies in the area of aesthetics and $14.69 \%$ in ophthalmic area, among other applications. It was observed that the future prospects for the use of latex have grown significantly over the past five years, generating benefits to society for your therapeutic action and for generating your jobs.

Keywords: biomaterial, biomedical engineering, health, medicine and latex.

\section{INTRODUÇÃO}

O látex natural é um líquido de aspecto leitoso, extraído da seringueira Hevea brasiliensis. O látex tem características interessantes na área da indústria para produção de pneus, porém há propriedade do látex que podem ser utilizados na indústria da biomédica, pois apresenta características como por exemplo: leveza, indolor na aplicação e remoção, impermeabilidade a micro-organismos, permeabilidade ao oxigênio e ao vapor d'água, facilidade de processamento, biodegradabilidade e biocompatibilidade (GALIANO et al., 2018).

O Brasil foi o principal produtor e exportador mundial do látex natural no final do século XIX e início do século XX, passando a ser importador desta matéria-prima a partir de 1950 (RICHTER, 2016).

Biomateriais são substâncias ou conjunto de substâncias naturais ou sintéticas, planejadas para substituir matéria viva não-funcional e que sejam biocompatíveis, reprodutíveis, acessíveis e biodegradáveis em situações especificas(BARREIROS et al., 2014; RODRIGUES, 2014). Para que um novo material possa ser incluído na área biomédica, são necessários conhecimentos básicos sobre a ciência que estuda os biomateriais, bem como as técnicas de caracterização físico-química (CHEN et al., 2016). De forma complementar, é preciso envolver a interação do biomaterial com células e organismos vivos, bem como constituir a biocompatibilidade e possíveis aplicações práticas na rotina clínica e cirúrgica (HU et al., 2018).

Biomateriais compõem partes de implantes médicos, dispositivos extracorpóreos e descartáveis, podendo ser implantados de maneira temporária ou permanentemente no corpo humano (LIU et al., 2014). O material substitutivo, para ser considerado ideal, deve ser de baixo custo de produção, fácil manipulação, promover crescimento dos tecidos no hospedeiro, 
Artigo de Revisão

Hegemonia - Revista Eletrônica do Programa de Mestrado em Direitos Humanos, Cidadania

e Violência/Ciência Política do Centro Universitário Unieuro

ISSN: 1809-1261

UNIEURO, Brasília, número 27 (Especial), 2019, pp. 7-42.

permitindo assim que o tecido cicatricial tenha força semelhante ao tecido normal (PADIL; MIROSLAV; VARMA, 2018). Encontram-se hoje no mercado inúmeros produtos para tratamentos de feridas e outras enfermidades que são acionados a partir de um "biomaterial". Estes são comumente apresentados em forma de filmes, espumas, géis ou membranas (GURYANOV; FIORUCCI; TENNIKOVA, 2016).

Algumas membranas com este material têm sido empregadas como próteses e enxertos médicos, devido às suas características de biocompatibilidade e estímulo natural à angiogênese, neste tipo de aproveitamento o método de fabricação do látex utilizado é o Natural Rubber Latex Biomedical(NRLB), que impede o emprego de produtos químicos como os carbonatos e o enxofre, fazendo com que seja eficaz apenas com o látex natural (GURYANOV; FIORUCCI; TENNIKOVA, 2016).

O látex está sendo um dos mais estudados devido sua eficácia e biocompatibilidade, aliado ás suas características de elasticidade, tensão máxima de tração, ductilidade e tenacidade, relacionadas à capacidade e facilidade do material ser adaptado em formatos compatíveis. Além disso, o látex está sendo testado no ser humano como material indutor de neoformação tecidual (CHEN; LIANG; THOUAS, 2013). Dessa forma, o objetivo deste trabalho é investigar as publicações científicas realizadas, nos últimos cinco anos, sobre as potencialidades do látex como biomaterial na área médica.

\section{METODOLOGIA}

Para obtenção das publicações científicas, sobre as potencialidades do látex como biomaterial na área médica, foram realizadas buscas nas bases dados Elsevier (CrossRef), Medline/Pubmed (NLM), Science Citation Index Expanded (Web of Science), Scopus(Elsevier),SCIELO, LILACS, Google acadêmico, Clinicaltrials.gov, Science Direct e da plataforma Periódicos CAPES. Acessados através do portal Periódicos CAPES, utilizou-se as palavras-chave "biomaterial", "biomedical engineering", "bealth", "medicine" elatex”, e com período de busca de 20142018. O processo de busca foi estipulado para documentos publicados nos últimos cinco anos, de 2014-2018. Estabeleceu-se como critério de inclusão artigos de revistas científicas revisados por pares. Utilizou-se para escrita deste artigo de revisão a ferramenta PRISMA (Preferred Reporting Items for Systematic Reviews and Meta-analyses) (MOHER et al., 2009). Os dados obtidos na 
Artigo de Revisão

Hegemonia - Revista Eletrônica do Programa de Mestrado em Direitos Humanos, Cidadania e Violência/Ciência Política do Centro Universitário Unieuro

ISSN: 1809-1261

UNIEURO, Brasília, número 27 (Especial), 2019, pp. 7-42.

publicação foram tabulados por referência, objetivo do trabalho, aplicação relatada sobre o uso de látex, resultados da publicação. Por fim, sumarizaram-se as informações na seção Discussões deste trabalho.

RESULTADOS

O processo de seleção dos artigos pode ser observado na Figura 1 a seguir.

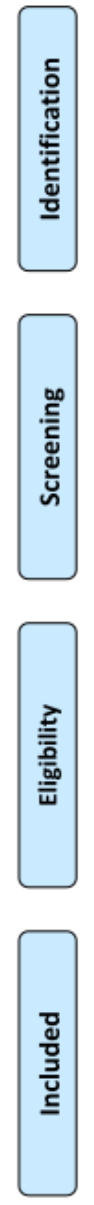

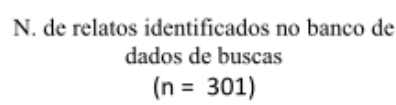

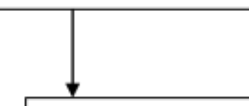

N. de relatos após eliminar os duplicados $(n=280)$

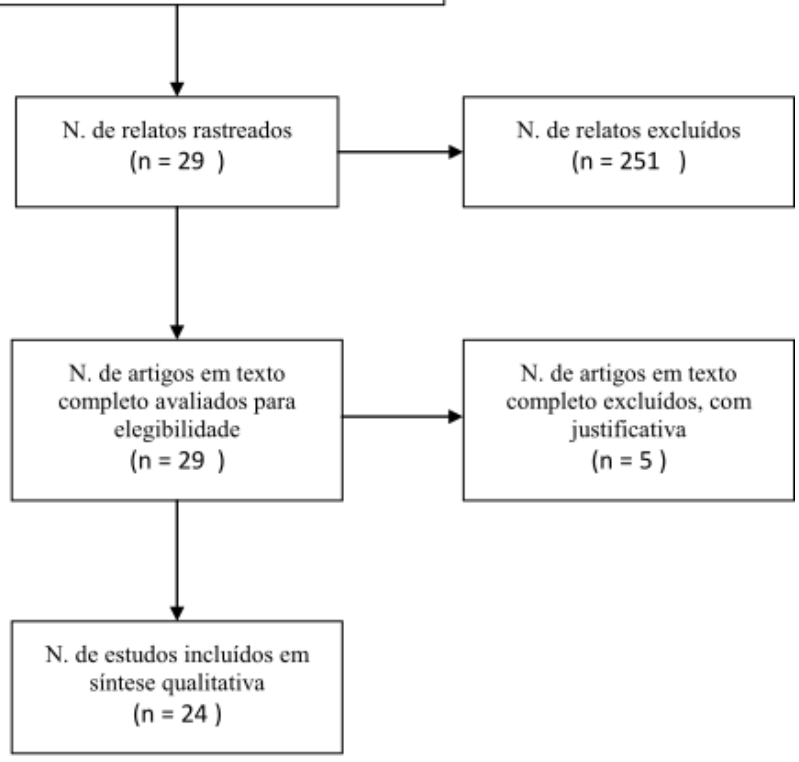

Figura 1- Dados quantitativos dos artigos pesquisados nas bases de dados escolhidas e critérios de inclusão e exclusão estabelecidos pelo trabalho. Fonte: Adaptado de Moher et al. (2009). 
Artigo de Revisão

Hegemonia - Revista Eletrônica do Programa de Mestrado em Direitos Humanos, Cidadania e Violência/Ciência Política do Centro Universitário Unieuro

ISSN: 1809-1261

UNIEURO, Brasília, número 27 (Especial), 2019, pp. 7-42.

Dos trabalhos selecionados sobre aplicação da membrana de látex na área médica obteve-se um percentual de $21,52 \%$ dos artigos associado à regeneração óssea. Para aplicação em enxerto de pele foi de 7,16\%, neoformação 2,63\%, feridas $8,58 \%$, membrana de látex aplicada à medicamentos 10,23\%, látex aplicado à queimadura 4,85\%, estética 14,69\%, estudos alergênicos $8,65 \%$, enxerto de veia $3,95 \%$, podologia $2,83 \%$ e na oftalmologia aplicado aos implantes oculares 14,91\% (Ver Figura 2).

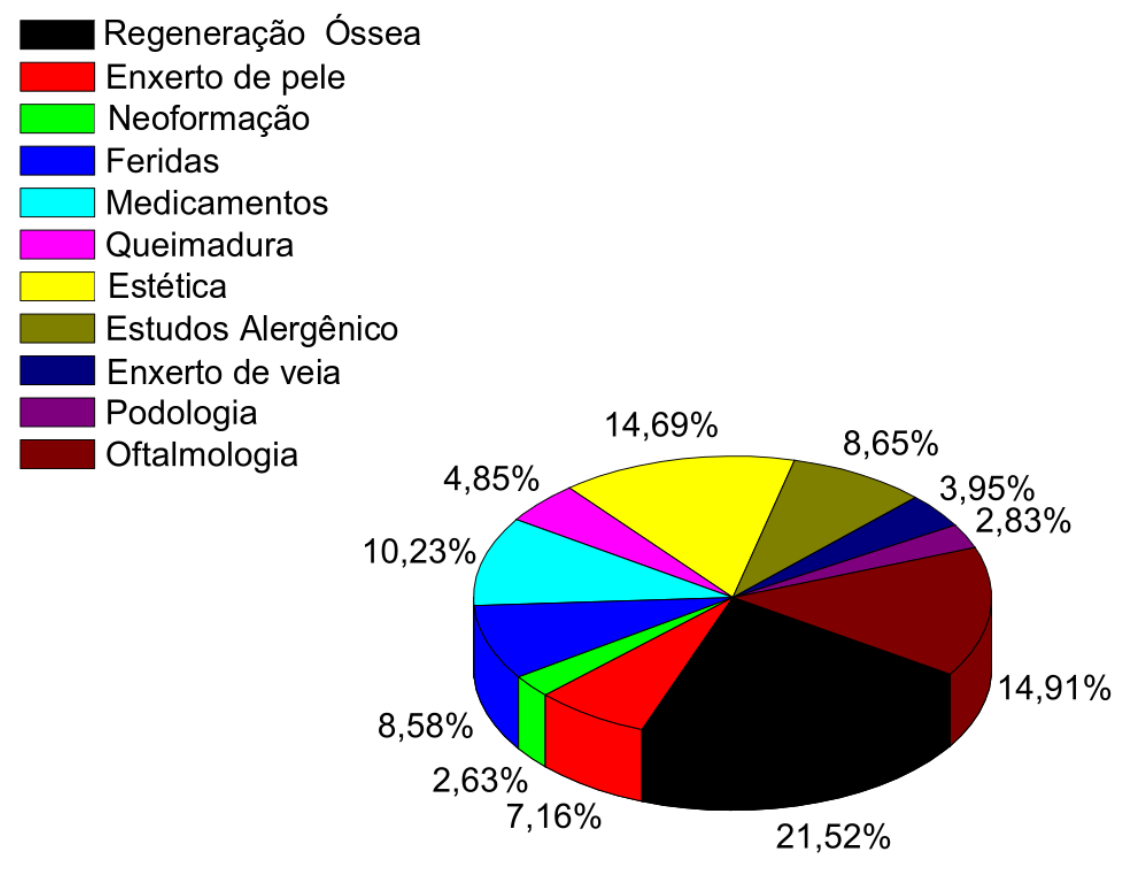

\section{Aplicação de látex na área médica}

Figura 2- Resultado das pesquisas nas bases de dados sobre aplicação de látex na área médica.

O estudo demonstrou que o látex possui das mais variadas aplicações na área médica, que ainda estão em pleno desenvolvimento, relacionadas à regeneração celular, óssea, e aplicações medicamentosas. Tal fato, demonstra que há um consenso entre os pesquisadores sobre as propriedades deste material promover a angiogênese e possuir biocompatibilidade satisfatória. A Tabela 1 está em destaque algumas aplicações na área médica, constam as informações dos autores e anos que foram produzidos os artigos e assunto abordado nos artigos lidos. 
Artigo de Revisão

Hegemonia - Revista Eletrônica do Programa de Mestrado em Direitos Humanos, Cidadania e Violência/Ciência Política do Centro Universitário Unieuro

ISSN: 1809-1261

UNIEURO, Brasília, número 27 (Especial), 2019, pp. 7-42.

Tabela 1-Artigos selecionados pelas buscas nas bases de dados e utilização dos critérios de inclusão e exclusão estabelecidos pelo presente trabalho.

\begin{tabular}{|c|c|c|c|}
\hline Autor & Objetivo do trabalho & $\begin{array}{l}\text { Aplicação relatada } \\
\text { sobre o uso de } \\
\text { látex }\end{array}$ & $\begin{array}{l}\text { Resultados do } \\
\text { trabalho }\end{array}$ \\
\hline $\begin{array}{l}\text { (STEELE et al., } \\
\text { 2013) }\end{array}$ & $\begin{array}{l}\text { Caracterização do } \\
\text { compósito colágeno- } \\
\text { celulose da membrana } \\
\text { de látex para de tecidos } \\
\text { antiaderentes ou } \\
\text { cardiovasculares }\end{array}$ & $\begin{array}{l}\text { Filmes compósitos } \\
\text { de colágeno- } \\
\text { celulose foram } \\
\text { avaliados } \\
\text { caracterizando } \\
\text { dispositivos } \\
\text { médicos } \\
\text { cardiovasculares. }\end{array}$ & $\begin{array}{l}\text { As propriedades } \\
\text { físicas e mecânicas } \\
\text { desses filmes } \\
\text { permitem que } \\
\text { sejam facilmente } \\
\text { manipuladas com } \\
\text { pouca preparação. }\end{array}$ \\
\hline $\begin{array}{c}\text { (MADUREIRA et } \\
\text { al., 2014) }\end{array}$ & $\begin{array}{l}\text { Estudos de látex de H. } \\
\text { Speciosa comparativo } \\
\text { das propriedades } \\
\text { medicinais que se } \\
\text { assemelham ao látex da } \\
\text { Hevea Brasiliensis para } \\
\text { finalidade de promover } \\
\text { a angiogênese, que é a } \\
\text { formação de novos } \\
\text { vasos sanguíneos. }\end{array}$ & $\begin{array}{l}\text { Estudo in vitro } \\
\text { sobre Análise } \\
\text { Físico-Química, } \\
\text { biocompatibilidade, } \\
\text { toxicidade e se } \\
\text { prover atividade de } \\
\text { angiogênise. }\end{array}$ & $\begin{array}{c}\text { Resultados } \\
\text { mostraram que o } \\
\text { H. speciosa e o látex } \\
\text { de H. brasiliensis } \\
\text { não diferem } \\
\text { significativamente } \\
\text { em sua } \\
\text { composição. }\end{array}$ \\
\hline $\begin{array}{l}\text { (MURBACH et al., } \\
\text { 2014) }\end{array}$ & $\begin{array}{c}\text { Estudo de } \\
\text { administração de } \\
\text { medicamento } \\
\text { antibiótico associado a } \\
\text { membrana de látex, para } \\
\text { assim diminuir riscos } \\
\text { inerentes a dosagem em } \\
\text { taxa para minimizar das } \\
\text { ocorrências. }\end{array}$ & $\begin{array}{l}\text { Membrana de látex } \\
\text { associada à } \\
\text { ciprofloxacina, que } \\
\text { é utilizado para } \\
\text { combater bactérias } \\
\text { em infecções } \\
\text { respiratórias, } \\
\text { urinárias, } \\
\text { gastrointestinais e } \\
\text { abdominais }\end{array}$ & $\begin{array}{c}\text { Os resultados } \\
\text { mostram que a } \\
\text { membrana pode } \\
\text { liberar CIP para } \\
\text { até } 59,08 \% \text { em } 312 \\
\text { horas. }\end{array}$ \\
\hline $\begin{array}{c}\text { (SILVEIRA et al., } \\
\text { 2014) }\end{array}$ & $\begin{array}{c}\text { Comparação da } \\
\text { propriedade } \\
\text { angeogênicas de } \\
\text { diferentes clones } \\
\text { estudados RRIM 600, } \\
\text { PB 235, GT1, PR 255 e } \\
\text { IAN } 873 \text { de Hevea } \\
\text { Brasiliensis encontrados } \\
\text { no Brasil. }\end{array}$ & $\begin{array}{l}\text { Estudo in vitro dos } \\
\text { diferentes tipos de } \\
\text { clones das árvores } \\
\text { que produz o látex. }\end{array}$ & $\begin{array}{c}\text { Membranas dos } \\
\text { clones RRIM } 600 \text { e } \\
\text { IAN } 873 \\
\text { induziram maior } \\
\text { proliferação } \\
\text { celular, sugerindo } \\
\text { maior bioatividade. }\end{array}$ \\
\hline $\begin{array}{l}\text { (FERREIRA et al., } \\
\text { 2014) }\end{array}$ & $\begin{array}{c}\text { Implatação de } \\
\text { membrana nas paredes } \\
\text { do estomago em } \\
\text { leporinos para assim }\end{array}$ & $\begin{array}{l}\text { Substituição aos } \\
\text { fragmentos da } \\
\text { parede do }\end{array}$ & $\begin{array}{l}\text { Biocompatibilidade } \\
\text { favorecendo a } \\
\text { regeneração das }\end{array}$ \\
\hline
\end{tabular}


Artigo de Revisão

Hegemonia - Revista Eletrônica do Programa de Mestrado em Direitos Humanos, Cidadania e Violência/Ciência Política do Centro Universitário Unieuro

ISSN: 1809-1261

UNIEURO, Brasília, número 27 (Especial), 2019, pp. 7-42.

\begin{tabular}{|c|c|c|c|}
\hline & $\begin{array}{c}\text { verificar a } \\
\text { biocompatibilidade, } \\
\text { capacidade de } \\
\text { cicatrização e possíveis } \\
\text { complicações. } \\
\text { Neoesôfago. }\end{array}$ & $\begin{array}{l}\text { estômago em } \\
\text { leporinos. }\end{array}$ & $\begin{array}{c}\text { partes lesionadas } \\
\text { do estomago. }\end{array}$ \\
\hline $\begin{array}{c}\text { (GOMES et al., } \\
\text { 2015) }\end{array}$ & $\begin{array}{l}\text { Estudo da membrana de } \\
\text { látex no tratamento de } \\
\text { fraturas expostas da } \\
\text { tíbia de ratos. }\end{array}$ & $\begin{array}{c}\text { Proteína } \\
\text { morfogenética } \\
\text { óssea } \\
\text { recombinante } \\
\text { humana (rhBMP-2) } \\
\text { em } 6 \text { grupos } \\
\text { distintos. }\end{array}$ & $\begin{array}{c}\text { O selante de } \\
\text { fibrina heteróloga } \\
\text { é biocompatível e a } \\
\text { consolidação óssea } \\
\text { do grupo BMP-2 }\end{array}$ \\
\hline $\begin{array}{c}\text { (DUTRA et al., } \\
\text { 2017) }\end{array}$ & $\begin{array}{c}\text { Caracterização das } \\
\text { propriedades físico- } \\
\text { química do látex da } \\
\text { papaína na angiogênese. }\end{array}$ & $\begin{array}{l}\text { Testes mecânicos e } \\
\text { químicos e estudo } \\
\text { in vitro para } \\
\text { verificar a } \\
\text { toxicidade. }\end{array}$ & $\begin{array}{c}\text { Preparação } \\
\text { curativos } \\
\text { interativos e } \\
\text { bioativos contendo } \\
\text { papaína a partir de } \\
\text { misturas de PVA e } \\
\text { polímeros de } \\
\text { alginato de cálcio. }\end{array}$ \\
\hline $\begin{array}{c}\text { (ARAÚJO et al., } \\
\text { 2017) }\end{array}$ & $\begin{array}{c}\text { Utilização da proteína } \\
\text { Hev b } 13 \text { especifica do } \\
\text { látex para tratamento de } \\
\text { sepse. }\end{array}$ & $\begin{array}{l}\text { Lesões pulmonares } \\
\text { de ratos septais. }\end{array}$ & $\begin{array}{l}\text { Demonstrando } \\
\text { declínio } \\
\text { significativo nos } \\
\text { leucócitos totais e } \\
\text { diferenciais. }\end{array}$ \\
\hline $\begin{array}{l}\text { (FLORIANO et al., } \\
\text { 2018) }\end{array}$ & $\begin{array}{c}\text { Estudo da } \\
\text { administração da taxa } \\
\text { medicamentosa drogas } \\
\text { por via transdérmica } \\
\text { para tratamento de } \\
\text { tendinites. }\end{array}$ & $\begin{array}{l}\text { Analise físico- } \\
\text { química para } \\
\text { verificar a } \\
\text { incorporação do } \\
\text { medicamento. }\end{array}$ & $\begin{array}{l}\text { Cetoprofeno foi } \\
\text { incorporado em } \\
\text { membranas de } \\
\text { látex natural para } \\
\text { administração de } \\
\text { medicamentos. }\end{array}$ \\
\hline $\begin{array}{c}\text { (GUERRA et al., } \\
\text { 2018) }\end{array}$ & $\begin{array}{l}\text { Estudo de látex } \\
\text { propriedades químicas } \\
\text { in vitro. }\end{array}$ & $\begin{array}{c}\text { Estudo in vitro da } \\
\text { viabilidade celular } \\
\text { da miscibilidade } \\
\text { epoxidativa. }\end{array}$ & Viabilidade celular. \\
\hline (PINHO et al., 2018) & $\begin{array}{c}\text { Utilização de lâmina de } \\
\text { látex de cicatrização } \\
\text { conjuntiva e a } \\
\text { neoangiogênese. }\end{array}$ & $\begin{array}{l}\text { Aplicação de } \\
\text { enxerto conjuntivo } \\
\text { em coelhos. }\end{array}$ & $\begin{array}{c}\text { Cicatrização } \\
\text { tecidual da } \\
\text { membrana de látex } \\
\text { se mostrou mais } \\
\text { lenta, porém não } \\
\text { demonstrando } \\
\text { diferenças no } \\
\text { resultado final para } \\
\text { a cicatrização } \\
\text { conjuntiva. }\end{array}$ \\
\hline
\end{tabular}


Artigo de Revisão

Hegemonia - Revista Eletrônica do Programa de Mestrado em Direitos Humanos, Cidadania e Violência/Ciência Política do Centro Universitário Unieuro

ISSN: 1809-1261

UNIEURO, Brasília, número 27 (Especial), 2019, pp. 7-42.

Os dados da Figura são referentes onde estão sendo estudada aplicação de látex na área médica, pode ser visto que o país que está ocorrendo estudos no setor é USA com 26.605, seguido pela Inglaterra e Austrália, Canadá e Índia com quantidade de pesquisa de 5.706, 5.040 e 3.029, respectivamente. Sendo selecionados os cinco países com maior número de publicações.

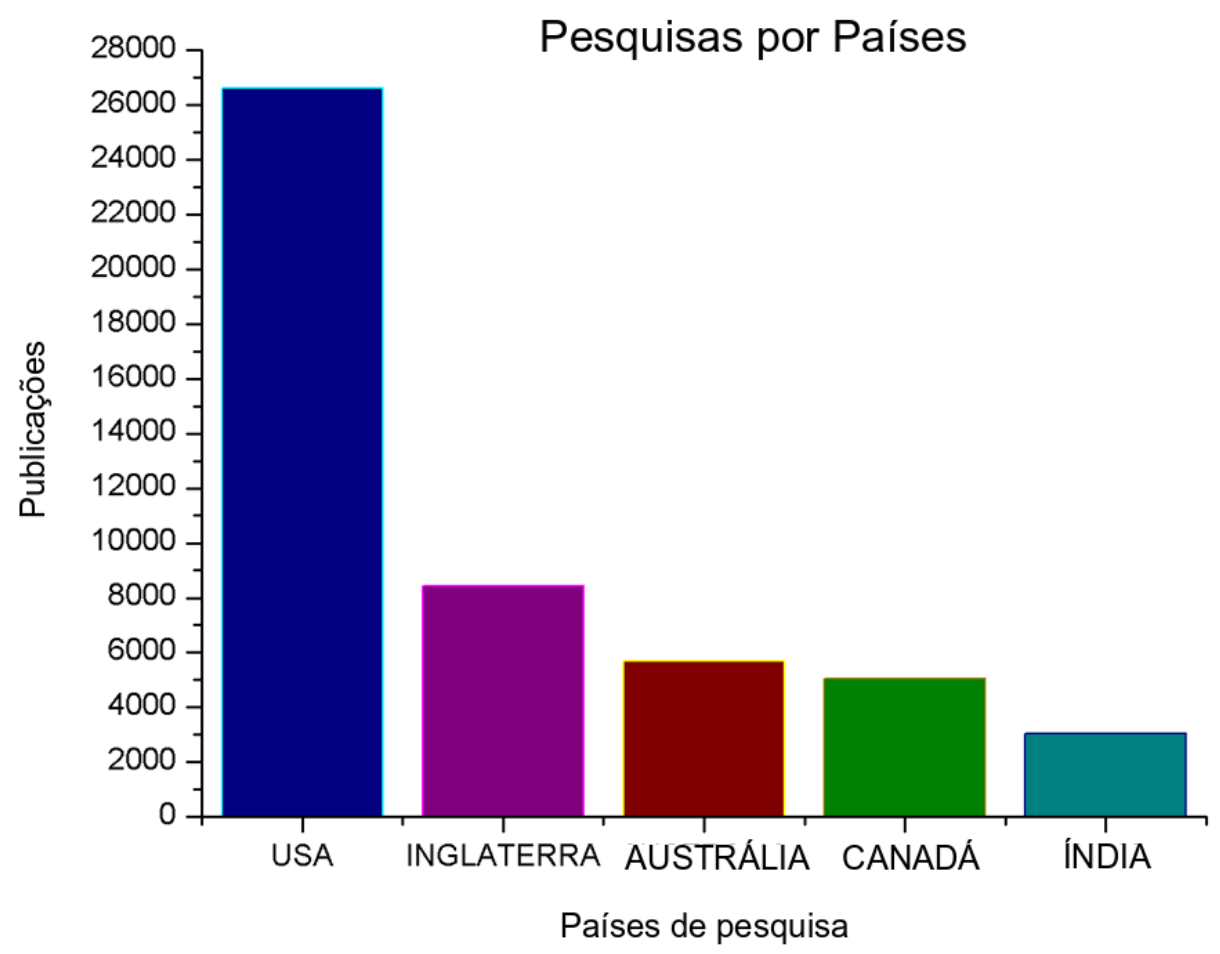

Figura 3 - Dados das regiões em que estão sendo estudada a aplicação látex na área médica. Adaptado de (Analytics, 2012).

\section{DISCUSSÃO}

Atualmente os biomateriais têm proporcionado aplicações com sucesso em, por exemplo: tratamento de feridas e doenças, e reparo ou substituição de órgãos e tecidos. Nota-se uma interessante atuação no desenvolvimento de próteses ortopédicas, placas ósseas, cimento ósseo, ligamentos e tendões artificiais, implantes dentários, dispositivos de reparação da pele, próteses de vasos sanguíneos entre outros.

Ferreira et al. (2014) relata que a membrana de látex natural foi utilizada pela primeira vez como prótese de uma fração do esôfago cervical de cães. Nesse estudo, no lugar da prótese, 
Artigo de Revisão

Hegemonia - Revista Eletrônica do Programa de Mestrado em Direitos Humanos, Cidadania

e Violência/Ciência Política do Centro Universitário Unieuro

ISSN: 1809-1261

UNIEURO, Brasília, número 27 (Especial), 2019, pp. 7-42.

formou-se um "neoesôfago" e seus resultados demonstraram que o látex apresentava propriedades indutoras de regeneração tecidual, sendo totalmente eliminado nas fezes dos animais após dez dias de pós-operatório. Observou-se que a biomembrana de látex natural também beneficiou a cicatrização conjuntiva e a neoangiogênese (PINHO et al., 2018). Trabalhos mais recentes confirmam excelentes propriedades, tais como: resistência mecânica, elasticidade, fácil manuseio e baixo custo do látex natural (ABERLE et al., 2014).

Em trabalho de Gomes et al. (2015), os biomateriais estão sendo considerados como materiais ou substâncias, diferentes de um fármaco, arquitetados para serem aplicados em um tecido, órgão ou ainda, para preencher alguma função no organismo, de uma forma geral, são utilizados em qualquer método ou propósito médico e/ou biomédico. $\mathrm{O}$ autor descreve um experimento com ratos, do tipo Wistar fêmeas, para testar a combinando BMP-2humano recombinante e proteína da Hevea brasiliensis (P-1) para tratar fraturas expostas da tíbia, observando como ocorre a regeneração óssea na presença dessas substâncias, o tratamento é feito por leituras histopatológicas e análise histológica, bem como a detecção análise imunohistoquímica. Obtendo resultados efetivos de cicatrização e possíveis aplicações futuras em seres humanos (GOMES et al., 2015).

Outra aplicação para uso de látex foi o estudo experimental dos benefícios antiinflamatório que uma proteína, conhecida por “Hev b 13”, retirada do látex natural de Hevea brasiliensis para tratamento de sepse, que é o quadro de doença infecciosa que responde há uma inflamação sistêmica grave (ARAÚJO et al., 2017).

Steele et al. (2013) apresenta em seu estudo in vitro e compara as propriedades mecânicas de crescimento celular e fazendo análise histológica de um filme compósito de colágeno e celulose para aplicações na regeneração cardiovascular e reparos musculoesqueléticos, para possíveis aplicações na área de biomateriais. O trabalho faz um comparativo do comportamento deste filme compósito em diferentes ambientes, úmidos e secos, analisando curvas anisotrópicas de tensão-deformação que imitava os tecidos moles do corpo.

Como o látex possui alta resistência mecânica e de baixo custo de aquisição, maleável e ainda possui propriedades de biocompatibilidade, além de estimular a angiogênese natural e fácil adesão celular tem grande potencial para aplicações na área médica dentre eles, a administração medicamentosa de taxa conhecida para atuação em tratamento infeccioso como descrito por Murbach et al. (2014) que apresenta como estudo o controle da taxa de administração de medicamento antibiótico no tratamento de infecções locais onde são instalados parafusos 
Artigo de Revisão

Hegemonia - Revista Eletrônica do Programa de Mestrado em Direitos Humanos, Cidadania

e Violência/Ciência Política do Centro Universitário Unieuro

ISSN: 1809-1261

UNIEURO, Brasília, número 27 (Especial), 2019, pp. 7-42.

externos de fixação e infecções remotas, para tanto utiliza o encapsular desse antibiótico pelo uso do látex borracha natural, tendo resultado satisfatório com estudo da taxa administrada, aplicando o método de difração de raios-X e espectroscopia de transformada de Fourier (FTIR).

Já o autor Guerra et al. (2018) faz um estudo daspropriedades químicasin vitro para avaliar o efeito na preparação das misturas com Poly (ácido láctico-co-glicólico) a fim de melhorar a compatibilidade química em relação ao Cellprene ${ }^{\circledR}$ e aumentar suas aplicações em engenharia de tecidos. Cellprene ${ }^{\circledR}$ é um biomaterial de mistura elastomérica reabsorvível angiogênica, patenteada pela Universidade Federal do Rio Grande do Sul.

O autor Floriano et al. (2018) apresenta um estudo controle da taxa medicamentosa para tratamento de tendinites, pois para patologias inflamatórias utiliza-se analgésicos potentes antiinflamatórios para atuar contra sintomas agudos e subagudos. Nesse estudo foi utilizado a membrana de látex natural incorporada ao analgésico cetoprofeno, que em geral é utilizado por longo prazo no tratamento, e pode acarretar em eventos incidentes sistêmicos atrelado ao seu uso. Logo para minimizar esses possíveis eventos, a impregnação medicamentosa na membrana gerou uma taxa de entrega controlada, demonstrando que não houve alteração na membrana na presença no medicamento.

Silveira et al. (2014) compara cinco clones (RRIM 600, PB 235, GT1, PR 255 e IAN 873) que produzem látex de borracha natural-NRL plantadas em plantações brasileira, buscando identificar suas diferenças em biocompatibilidade e toxidade que podem apresentar na presença de amônia usada durante a coleta de látex como agente anticoagulante. Para tanto, faz uso do estudo in vitro em células de fibroblastos de camundongo por três períodos, 24, 48 e $72 \mathrm{~h}$ na presença da membrana de látex esterilizada. Além do estudo in vitro, foi realizado o estudo in vivo em coelhos, sendo as membranas implantadas subcutaneamente em coelhos. Obtendo como resultado os clones de plantas que apresentam induzirão maior proliferação celular foram as RRIM 600 e IAN 873 tanto no estudo in vitro como no in vivo. Já o resultado para presença de amônia nos teste realizados apresentou citotóxico e genotóxico efeitos em culturas, bem como necrose e aumento de células inflamatórias nos tecidos do coelho perto do implante.

No caso de Dutra et al. (2017) cita-se o uso do látex da papaína para tratamentos de doenças cutâneas, que auxiliam na cicatrização de feridas e no tratamento de queimaduras, 
Artigo de Revisão

Hegemonia - Revista Eletrônica do Programa de Mestrado em Direitos Humanos, Cidadania

e Violência/Ciência Política do Centro Universitário Unieuro

ISSN: 1809-1261

UNIEURO, Brasília, número 27 (Especial), 2019, pp. 7-42.

utilizando métodos para caracterizar esses biofilmes quando a sua miscibilidade da composição da mistura, analisando suas propriedades químicas.

Em trabalho de Madureira et al. (2014) investiga-se o potencial do biomaterial látex $H$. Speciosa para estimular a angiogênese, processo esse importante na proliferação celular ou para promover a cicatrização de feridas. Sendo estudadas as propriedades físicas e químicas de biomembranas avaliando através de testes in vitro a citotoxicidade e genotoxicidade pelo uso da membrana corioalantóica de ovo de galinha. Resultando em biomaterial de potencial elevado em aplicações de tratamento médicas, pois possui características semelhantes a da Hevea Brasiliensis.

Determinados autores descreveram que biomateriais tiveram utilizações sugeridas como molde de enxerto de pele, agente cicatrizador, material para sutura, agente antimicrobiano, géis, cápsulas e soluções. Os biomateriais oriundos do látex têm sido vistos como aceleradores de reparação tecidual e que oferecem a capacidade de acrescentar a produção da matriz extracelular. Os Biomateriais são substâncias ou concertos de substâncias sintéticas ou naturais, projetados para suprirem parte ou função orgânica de forma segura, econômica e aceitável fisiologicamente, atuando em contato direto com tecidos vivos e com sistemas biológicos podendo ser de uso temporário ou definitivo, os quais propor-se tratar ou substituir, parcial ou totalmente, qualquer tecido, órgão ou função do corpo (BERTOLINO, 2018).

Os biomateriais estão sendo considerados como materiais ou substâncias, diferentes de um fármaco, arquitetados para serem aplicados em um tecido, órgão ou ainda, para preencher alguma função no organismo, de uma forma geral, são utilizados em qualquer método ou propósito médico e/ou biomédico (MAGNO, 2013).

\section{CONCLUSÃO}

Os biomateriais vêm acarretando potenciais para o mercado e para a engenharia biomédica, motivando os pesquisadores cada dia mais a busca por mais evidências caracterizando os biomateriais como tecnologias de alta potência para o século XXI. A borracha natural retirada da seringueira tem representado uma grande potencialidade também nas aplicações industriais, tais como pneumáticos, que consomem quase $75 \%$ da produção mundial, mais mesmo assim ela vem crescendo com excelência na área médica principalmente em materiais cirúrgicos, adesivos e películas. 
Artigo de Revisão

Hegemonia - Revista Eletrônica do Programa de Mestrado em Direitos Humanos, Cidadania

e Violência/Ciência Política do Centro Universitário Unieuro

ISSN: 1809-1261

UNIEURO, Brasilia, número 27 (Especial), 2019, pp. 7-42.

A qualidade destes produtos industrializados de borracha depende de outros fatores da qualidade da borracha crua, o que explica a procura cada vez maior da indústria e dos laboratórios de engenharia biomédica onde são estudados diariamente por cientistas e estudantes buscando a qualidade e mais evidências com mais propriedades homogêneas de qualidade, sendo que a produtividade da borracha natural estar em São Paulo sempre envolvendo três segmentos que são: produtividade, benefício e indústria. Mais existe ainda uma falta de uma integração entre os três segmentos deixando assim motivos de esgotamento dentro dessa cadeia de ações, pois enquanto o segmento produtivo se preocupa com produtividade, a indústria e a qualidade uniforme da matéria prima se tornam de forma prática uma de borracha crua, para que os pesquisadores e empresas tenham dentre mão a qualidade da borracha para melhor satisfação.

O presente trabalho teve como objetivo a busca de evidências que pudessem demonstrar as potencialidades do biomaterial látex, visando aplicações biomédicas e tecnológicas. Os resultados obtidos mostraram que o biomaterial látex não apresenta características tóxicas às células e nem ao DNA. Os resultados das análises bibliográficas indicam que o látex é um material de baixo custo e que, além disso, pode ser empregado para neoformação tecidual e enxertos em pacientes. Observou-se que os países com maior percentual de pesquisas na área fora, respectivamente do maior para o menor: EUA, Inglaterra, Austrália, entre outros. Tais fatos, demonstram que as pesquisas para aplicação do látex na medicina têm crescimento significativamente nos últimos anos. Dessa forma, visualiza-se um campo amplo de evidências já confirmadas e outras a confirmar, principalmente na necessidade de mais pesquisas sobre a eficácia do uso deste material em seres humanos.

\section{AGRADECIMENTOS}

Agradecemos à Universidade de Brasília-UnB e à Faculdade Gama-UnB/FGA pelo suporte na realização deste trabalho. Agradecemos também à CAPES pela disponibilização de bolsas de estudo e pesquisa. 
Artigo de Revisão

Hegemonia - Revista Eletrônica do Programa de Mestrado em Direitos Humanos, Cidadania e Violência/Ciência Política do Centro Universitário Unieuro

ISSN: 1809-1261

UNIEURO, Brasília, número 27 (Especial), 2019, pp. 7-42.

\section{REFERÊNCIAS}

ABERLE, T. et al. Cell-Type Specific Four-Component Hydrogel. PLoS ONE, v. 9, n. 1, 2014.

ARAÚJO, L. A. et al. Protein from Hevea brasiliensis "Hev b 13" latex attenuates systemic inflammatory response and lung lesions in rats with sepsis. Brazilian Journal of Biology, v. 78, n. 2, p. 271-280, jul. 2017.

BARREIROS, V. C. P. et al. Morphological and morphometric analyses of crushed sciatic nerves after application of a purified protein from natural latex and hyaluronic acid hydrogel.

Growth Factors, v. 32, n. 5, p. 164-170, 2014.

CHEN, Q.; LIANG, S.; THOUAS, G. A. Elastomeric biomaterials for tissue engineering.

Progress in Polymer Science, v. 38, p. 584-671, 2013.

CHEN, Z. et al. Osteoimmunomodulation for the development of advanced bone biomaterials. Biochemical Pharmacology, v. 19, n. 6, p. 304-321, 2016.

DUTRA, J. A. P. et al. European Journal of Pharmaceutics and Biopharmaceutics Papain wound dressings obtained from poly ( vinyl alcohol)/ calcium alginate blends as new pharmaceutical dosage form : Preparation and preliminary evaluation. European Journal of Pharmaceutics and Biopharmaceutics, v. 113, p. 11-23, 2017.

FERREIRA, A. R. S. et al. Avaliaç ão macroscópica e microscópica de implante de biomembrana em estômago de coelhos (oryctolagus cuniculus). Arquivo Brasileiro de Medicina Veterinaria e Zootecnia, v. 66, n. 1, p. 177-184, 2014.

FLORIANO, J. F. et al. Ketoprofen Loaded in Natural Rubber Latex Transdermal Patch for Tendinitis Treatment. Journal of Polymers and the Environment, v. 26, n. 6, p. 2281-2289, 2018.

GALIANO, F. et al. Advances in biopolymer-based membrane preparation and applications. Journal of Membrane Science, v. 564, n. May, p. 562-586, 2018.

GOMES, E. et al. Acta Histochemica A new heterologous fibrin sealant as scaffold to recombinant human bone morphogenetic protein-2 ( rhBMP-2) and natural latex proteins for the repair of tibial bone defects. Acta Histochemica, v. 117, n. 3, p. 288-296, 2015.

GUERRA, N. B. et al. Chemical and in vitro characterization of epoxidized natural rubber blends for biomedical applications. 2018.

GURYANOV, I.; FIORUCCI, S.; TENNIKOVA, T. Receptor-ligand interactions : Advanced 
Artigo de Revisão

Hegemonia - Revista Eletrônica do Programa de Mestrado em Direitos Humanos, Cidadania e Violência/Ciência Política do Centro Universitário Unieuro

ISSN: $1809-1261$

UNIEURO, Brasília, número 27 (Especial), 2019, pp. 7-42.

biomedical applications. Materials Science \& Engineering C, v. 68, p. 890-903, 2016.

HU, H. et al. Angiogenesis and Full-Thickness Wound Healing Efficiency of a Copper-Doped Borate Bioactive Glass/Poly(lactic-co-glycolic acid) Dressing Loaded with Vitamin E in Vivo and in Vitro. 2018.

LIU, M. et al. Progress in Polymer Science Recent advance in research on halloysite nanotubes-polymer nanocomposite. Progress in Polymer Science, v. 39, n. 8, p. 1498-1525, 2014.

MADUREIRA, L. et al. Hancornia speciosa latex for biomedical applications : physical and chemical properties , biocompatibility assessment and angiogenic activity. p. 2153-2162, 2014. MOHER, D. et al. Preferred reporting items for systematic reviews and meta-analyses: The PRISMA statement. PLoS Medicine, v. 6, n. 7, 2009.

MURBACH, H. D. et al. Ciprofloxacin Release Using Natural Rubber Latex Membranes as Carrier. v. 2014, 2014.

PADIL, V. V. T.; MIROSLAV, Č.; VARMA, R. S. Tree gum-based renewable materials : Sustainable applications in nanotechnology, biomedical and environmental fi elds. v. 36, n. August, p. 1984-2016, 2018.

PINHO, E. C. C. M. DE et al. The study of the use of a latex biomembrane and conjunctival autograft in rabbit conjunctiva wound healing. Arquivos Brasileiros de Oftalmologia, v. 81, n. 2, p. 125-129, 2018.

\section{RICHTER, V. B. Evidências na Prática de Cicatrização Tecidual com Biomembrana de}

Látex. [s.l: s.n.].

RODRIGUES, L. B. Biomaterials applications in orthopaedics. v. 9, n. 2, p. 63-76, 2014.

SILVEIRA, L. et al. Biocompatibility studies of natural rubber latex from different tree clones and collection methods. p. 461-470, 2014.

STEELE, T. W. J. et al. Collagen - cellulose composite thin films that mimic soft-tissue and allow stem-cell orientation. p. 2013-2027, 2013. 